\title{
An UnusualPresentation of Sudden Death of a Non- Lactating Female with Mastitis
}

\author{
Dilhani Amarasinghe ${ }^{1 *} ه$ (iD), Rao Valarie ${ }^{1}$, Dierksen Jennifer ${ }^{1}$, Collins Kim $^{2}$, Rohan P \\ Ruwanpura $^{3}$ \\ ${ }^{1}$ Office of the Medical Examiner, North Jefferson street, District IV, State of Florida, USA. \\ ${ }^{2}$ Newberry Pathology Associates, Newberry, South Carolina, USA \\ ${ }^{3}$ Office of the Judicial Medical Officer, Teaching Hospital, Karapitiya, Galle, Sri Lanka.
}

Sudden death of a young female within a short duration of illness needs a proper death investigation to ascertain the cause, mechanism and manner of death. It is mandatory to have a medico-legal investigation into such deaths in order to rule out or confirm such doubts. A young, non-lactating female with a history of drug abuse was pronounced dead within a few hours of admission to the Emergency Department. The clinico-pathological correlation confirmed the cause of death as severe sepsis following acute mastitis due to Staphylococcus aureus and Streptococcus pyogens infection. The manner of death was deemed natural. Due to the delicate nature of the breast tissue, prompt and appropriate management of breast infections is reiterated. Severe sepsis caused by acute mastitis is one of the rare outcomes that may be discovered at autopsy. We report the importance of comprehensive forensic autopsy including ancillary investigations in a case of sudden death of a non-lactating female.

Keywords: Bleeding, Per-rectal, Diverticulosis, Jejunum, Autopsy

Copyright: @ 2018 with the Medico-legal Journal of Sri Lanka.

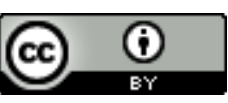

This is an open-access article distributed under the terms of the Creative Commons Attribution 4.0 International License, which permits unrestricted use, distribution and reproduction in any medium provided the original author and source are credited.

Funding: None, Competing interests: None

Received:20 Oct 2018 Accepted revised version:15 Dec 2018 Published: 30 December 2018

*Corresponding author:Amarasinghe D, E-mail address: dihani678@gmail.com, $\bigotimes$

http://orcid.org/0000-0001-666868-0194

Cite this article as:Amarasinghe D, Rao VJ, Dierksen J, Collins KA, Ruwanpura PR. An unusual Presentation of Sudden Death of a Non-Lactating Female with Mastitis. . Medico-Legal Journal of Sri Lanka, 2018;6(2):92-94.

DOI: http://dx.doi.org/10.4038/mljsl.v6i2.7382

\section{Introduction}

The investigation ofsudden death in an adult is often complex and requires coordination between multiple agencies including law enforcement, clinicians, medicolegal death investigators and forensic pathologists. Prior to performing the autopsy, background history, witness statement, scene examination, medical history, and details from emergency medical personnel are important to obtain. The forensic pathologist must be able to conduct a comprehensive forensic autopsy and be aware of the specific challenges related to determining the cause of sudden death.

\section{Case History}

We present the case of 34-year-old, non-lactating female with a history of drug abuse who was pronounced dead within a few hours of admission to the Emergency Department (ED). The only history provided by her relativewas worsening of a skin rash of the breasts over a span of few hours during the hot summer. She was admitted to ED in a state of coma. She died within a few hours despite medical management without a clinical diagnosis. 
At autopsy, the only significant external findings were an exfoliating skin rash over the breasts and early onset of decomposition. Upon sectioning of the breast, the tissue showed soft consistency and exudate composed of a yellow-tan purulent material. No hard areas or abscess identified.Axillary lymph nodes were unremarkable.

Microscopic examination of the breast tissue confirmed non-lactating status and revealed acute mastitis with breast lobules and ducts infiltrating with neutrophilic inflammation (Fig. 01). Acute inflammation extended into surrounding tissues (Fig. 02).

Microbiology cultures of blood and the breast exudate swab were both positive for Staphylococcus aureus and Streptococcus pyogens. The toxicological analysis did not demonstrate significant findings.

The lungs were congested and oedematous. The spleen was soft and the adrenals had haemorrhages. The cause of death was ascertained as severe sepsis following acute mastitis due to Staphylococcus aureus and Streptococcus pyogens infection.

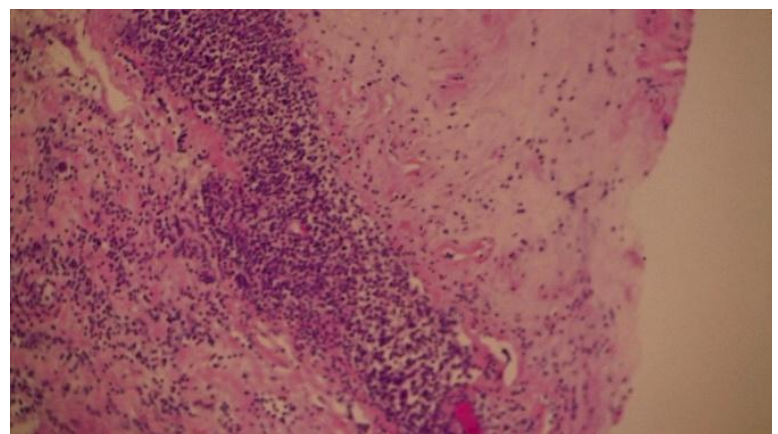

Figure 01: Photomicrograph shows breast lobules and ducts with infiltrating neutrophilic inflammation. $\mathrm{H} \& \mathrm{E} \times 100$

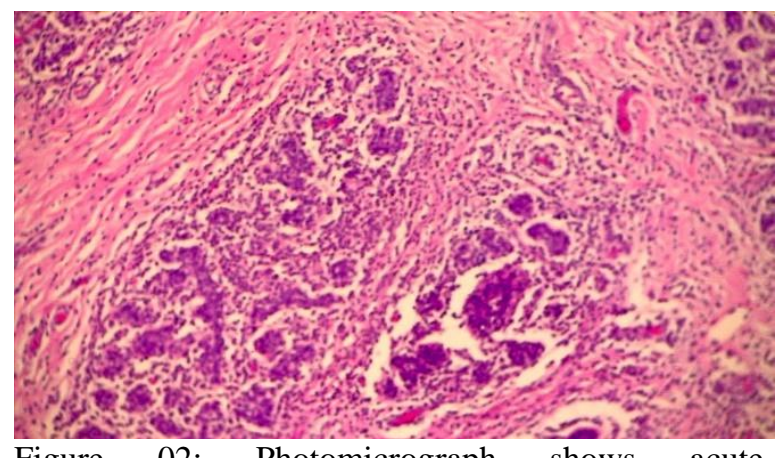

Figure 02: Photomicrograph shows acute inflammation extends into surrounding tissue. $H \& E x$ 100

\section{Discussion}

An inflammatory disease of the female breasts encompasses a large spectrum of diseases ranging from acute infective diseases to chronic autoimmune disease. $^{[1,2]}$

Acute inflammation of the breast usually occurs in lactating women which can be attributed due to structural changes associated with lactation, wrong feeding techniques, crack nipples due to poor sucking techniques. Most women are in the reproductive age group and less commonly in menopausal women.Currently, with the latest fashion of nipple piercing, the incidence of non-puerperal mastitis has increased. Acute inflammation of the breast may present as mild superficial mastitis to deep abscesses. ${ }^{[2,3,4,5]}$ However, in this case, though she was in her reproductive age, she had non-lactating breasts and did not show abscesses.

Acute mastitis is most often caused by a variety of causative bacteria including Staphylococcus aureus, Streptococcus group B, Klebsiella pneumonia and, Methicillin resistant Staphylococcusaureus ${ }^{[3]}$ In this case, the deceased had histological and toxicological evidence of acute mastitis due to Staphylococcus aureus and Streptococcus pyogens.

S. aureus is also an invasive pathogen and frequent cause of skin and soft tissue infections as well as bacteremia. Once the pathogen enters the bloodstream, $S$. aureus replicates and disseminates to many different sites, causing severe disease manifestations such as sepsis, infective endocarditis, and deep-seated abscesses in virtually every organ tissue ${ }^{[6,}{ }^{7]}$ However, in this case, before the development of these complications, she went to septic shock state.

Characteristically, Streptococcal pyogen infection begins at a site of trivial or even unapparent trauma or in an operative incision. The initial lesion may appear only as an area of mild erythema but undergoes a rapid evolution over the next 24-72 hours. The inflammation becomes more pronounced and extensive, the skin becomes dusky and then purplish and bullae containing yellow or hemorrhagic fluid appear. Bacteremia is frequently present, and metastatic abscesses may occur. Mortality rates are high, even with appropriate treatment. ${ }^{[7,8,} 9$, ${ }^{10]}$ Similarly, in this case, the deceased had a skin rash over the breasts which worsened over a span of a few hours. 
Sepsis is a syndrome of physiologic, pathologic, and biochemical abnormalities induced by infection and, is a major public health concern, accounting for more than $\$ 20$ billion $(5.2 \%)$ of total US hospital costs in 2011. Sepsis complicated by organ dysfunction was termed severe sepsis, which could progress to toxic shock syndrome. ${ }^{[8]}$ Both Staphylococcus aureus and Streptococcus pyogens can cause sepsis.In this case, microbiological studies confirm the presence of the above organisms.

Toxic shock syndrome (TSS) is an acute, multisystem, toxin-mediated illness, often result in multiorgan failure. ${ }^{[11]}$ TSS results from the ability of bacterial toxins to act as super antigens. It results in tissue damage, disseminated intravascular coagulation and organ dysfunction.Sudden deterioration of her condition points towards the toxic shock syndrome associated with sepsis.

With this clinical history, autopsy findings and the clinico-pathological correlation, the cause of death was certified as severe sepsis following acute mastitis due to Staphylococcus aureus and Streptococcus pyogens infections.

\section{Conclusion}

This case emphasizes the importance of a complete autopsy with ancillary autopsy studies in a case of sudden death of a young female. The clinicopathological correlation confirmed the cause of death as severe sepsis following acute mastitis due to Staphylococcus aureus and Streptococcus pyogens infectionsThe manner of death was deemed natural. Due to the delicate nature of the breast tissue, prompt and appropriate management of breast infections is essential. Severe sepsis caused by acute mastitis is one of the rare outcomes that may be discovered at autopsy as in the current case.

\section{References}

1. Al Nazer M. Idiopathic granulomatous lobular mastitis: a forgotten clinical diagnosis. Saudi Med J. 2003;24(12):1377-89.

2. Bukharie H, AbdelHadi M, Larbi E, Saeed I. Emergence of Methicillin-Resistant Staphylococcus aureus as a community pathogen. DiaMicrobio\& Infect Dis J. 2001;40:1-.

3. Jain BK, Sehgal VN, Jagdish S, Ratnakar C, Smile SR. Primary actinomycosis of the breast: a clinical review and case report. J Dermatol. 1994;21(7):497-500.
4. Simpson AJ, Jumaa PA, Das SS. Breast abscess caused by Nocardiaasteriodes. J Infect. 1995;30(3):266-7.

5. BJun SY, Jang J, Ahn SH, Park JM, Gong G. Paragonimiasis of the breast. Report of a case diagnoses by fine needle aspiration. ActaCytol. 2003;47(4):685-7.

6. Singer M, Deutschman CS, Seymour CW, Shankar-Hari M, Annane D, Bauer M, et al. The third international consensus definitions for sepsis and septic shock (sepsis-3). JAMA. 2016;315(8):801-10.

7. Bone RC, Balk RA, Cerra FB, Dellinger RP, Fein AM, Knaus WA, et al. Definitions for sepsis and organ failure and guidelines for the use of innovative therapies in sepsis. The ACCP/SCCM Consensus Conference Committee. American College of Chest Physicians/Society of Critical Care Medicine. Chest. 1992;101(6):1644-55.

8. Levy MM, Fink MP, Marshall JC, Abraham E, Angus D, Cook D, et al. 2001 SCCM/ESICM/ACCP/ATS/SIS international sepsis definitions conference. Crit Care Med. 2003;31(4):1250-6.

9. Kaukonen KM, Bailey M, Pilcher D, Cooper DJ, Bellomo R. Systemic inflammatory response syndrome criteria in defining severe sepsis. N Engl J Med. 2015;372(17):1629-38.

10. Hayashi T, Nakamura T, Takaoka A. Pattern recognition receptors. Jpn J ClinImmunol. 2011;34:329-45.

11. Schaefer L. Complexity of danger: the diverse nature of damage-associated molecular patterns. J Biol Chem. 2014;289(51):35237-45.

12. Opitz B, van Laak V, Eitel J, Suttorp N. Innate immune recognition in infectious and noninfectious diseases of the lung. Am J RespirCrit Care Med. 2010;181(12):1294-309.

13. Okusawa S, Gelfand JA, Ikejima T, Connolly RJ, Dinarello CA. Interleukin 1 induces a shocklike state in rabbits. Synergism with tumour necrosis factor and the effect of cyclooxygenase inhibition. J Clin Invest. 1988;81(4):1162-72. 